https://doi.org/10.48009/1_iis_2006_129-133

\title{
THE ROLE OF LEARNING STYLES IN THE TEACHING/LEARNING PROCESS
}

\author{
Nancy Csapo, Central Michigan University, csapo1n@cmich.edu \\ Roger Hayen, Central Michigan University, hayen1rl@cmich.edu
}

\begin{abstract}
This study is an analysis of learning style types for a variety of students at different grade levels. Over 2,000 students completed a questionnaire to determine if their learning style was auditory, visual, or tactile/kinesthetic. The purpose of this study was to increase faculty awareness and understanding of the role of learning styles in the teaching/learning process. A review of the literature was completed along with analysis of the data to determine how learning style type affects the teaching/learning process. The results suggest a focus on the kinesthetic learning style for information technology courses.
\end{abstract}

Keywords: Learning Styles, Auditory, Visual, Kinesthetic, Teaching/Learning Process, Occupational Areas, Effective Teaching

\section{INTRODUCTION}

Learning styles are individual differences in learning [4]. An individual's learning style "is the way he or she concentrates on, processes, internalizes, and remembers new and difficult academic information or skills" [7, p. 1]. Individuals approach learning differently due to differences in their learning styles. A person's approach to learning is a relatively stable indicator of how they perceive, interact with, and respond to the learning environment [8].
Understanding learning styles and the role of learning styles in the teaching/learning process is a key component in effective teaching. According to Sarasin, "teaching cannot be successful without a knowledge of learning styles and a commitment to matching them with teaching styles and strategies" [6, p. 7]. Utilizing learning style theory in the classroom is extremely beneficial at all educational levels for a variety of reasons. Some research has found a relationship between occupational preferences and learning style type. In addition, student's learning styles have been shown to be affected by their educational experiences, particularly at the postsecondary level. Individuals pursuing careers in information technology (IT) typically encounter a professional work environment that exploits extensive problem solving which draws upon their abilities with a kinesthetic learning style. Therefore knowledge of learning styles is useful in designing classroom activities that support the development of this learning style.

A number of learning style theories exist. Learning style theorists have identified specific characteristics of learning and have organized these characteristics into specific "classifications" of learners. Sarasin's synthesis of these theories is designed to provide an approach "that can be easily translated into strategies in a college or university classroom setting" $[6, \mathrm{p}$. 17]. Table 1 provides a framework of these theorists and shows their relationship to Sarasin's approach $[6$, p. 18].

Table 1. Synthesis of Learning Style Theories

\begin{tabular}{|l|l|l|l|}
\hline Theorist & Characteristics of Learners & \multicolumn{2}{l|}{} \\
\hline Sarasin & Auditory & Visual & $\begin{array}{l}\text { Tactile/ } \\
\text { Kinesthetic }\end{array}$ \\
\hline Gregorc/Butler & $\begin{array}{l}\text { Abstract/ } \\
\text { Sequential }\end{array}$ & Random/Concrete & Concrete \\
\hline Sims \& Sims & Cognitive & Perceptual & $\begin{array}{l}\text { Behavioral/ } \\
\text { Affective }\end{array}$ \\
\hline McCarthy & Analytic & Imaginative & Dynamic \\
\hline Harb, Durrant, \& Terry & $\begin{array}{l}\text { Abstract/ } \\
\text { Reflective }\end{array}$ & Concrete & $\begin{array}{l}\text { Active/ } \\
\text { Concrete }\end{array}$ \\
\hline
\end{tabular}




\section{RESEARCH QUESTIONS AND METHODOLOGY}

A review of the literature was conducted to answer two of the four research questions:

(1) How does learning style type affect the teaching/learning process?

(2) Is there a difference in preferred learning style based on academic program and/or occupation?

A study was conducted to gather data to answer the two remaining research questions:

(3) Is there a difference in the strength of student learning style preferences based on gender, race, or geographic location?

(4) Do students' learning style types change as they progress through their education?

Data was gathered at five public school districts in three states at the secondary, middle school, and elementary level. A 36-item descriptive survey instrument was administered to students to determine the type and strength of their learning style (auditory, visual, or kinesthetic). A total of 2,170 students, grades 4-12, were surveyed. There were 1,179 female and 991 male students who completed the survey.

\section{RESULTS}

Results are presented for each of the four research questions. First, the results from the literature search are considered, then, the findings from the data analysis are addressed.

\section{(1) Learning Styles and the Teaching/Learning Process}

A mismatch between the learning style of faculty and students has been shown to increase the disparity between how faculty teach and how students learn. This mismatch results in an ineffective learning process in the classroom. "The notion that all cognitive skills are identical at the collegiate level or in different training programs smacks of arrogance and elitism by either sanctioning one group's style of learning while discrediting the styles of others or ignoring individual differences altogether" $[8, \mathrm{p} . \mathrm{xi}]$. Research shows an increase in grade point average occurs when teacher and student learning style more closely matches [2].

Students vary in the way they process and understand information. Many instructors at the postsecondary level still do not realize the significance of these differences in how their students approach learning; and as a result, these instructors do not attempt to respond to these differences in how they teach [8]. Teachers must understand the learner (students) to be learner centered [1]. The increasingly diverse student body requires the use of a wide variety of teaching methods and materials. For example, research shows that gifted students prefer to learn either by themselves or with an authoritative teacher. They seldom want to learn with classmates. Characteristic of lower achieving students is their poor auditory memory. "Their inability to remember facts through lecture, discussion, or reading contributes to their low performance... where most instruction is delivered by teachers talking and students listening or reading" [7] (p. 5]. Particularly important for university faculty to understand is that individual differences (including differences in learning styles) increase with age for postsecondary students [6].

Sarasin outlines four steps to teaching more effectively at the postsecondary level. First, teachers must understand how they learn. Second, teachers must consider how they teach since we tend to teach toward our own learning preferences. Third, teachers must assess how their students learn and lastly, teachers must find ways to accommodate their students' learning styles [6]. In addition, when students understand their learning style preferences, research has shown they are more successful learners [3]. Students reported that early knowledge of their learning style type affected how they adapted to and strengthened their strategies for learning, including how they developed their study habits [3].

\section{(2) Learning Style Type and Choice of Academic Program and/or Occupation}

Kolb explains the factors that shape and influence learning styles by identifying "five particular levels of behavior: Personality types, early educational specialization, professional career, current job role, and adaptive competencies" [5, p. 7]. Our individual learning style is influenced throughout our lives by these different factors. For example, early educational experiences shape our learning style "by instilling positive attitudes toward specific sets of learning skills and by teaching us how to learn" [5, p. 8]. College education also has been shown to shape students' learning style preferences [4]. As we progress through educational experiences, the level of specialization increases, resulting in additional influence of our orientation toward learning.

According to Kolb, a tendency toward specific learning style types exists within particular 
undergraduate majors. For example, individuals with various undergraduate liberal arts majors differed in their predominant learning style type than those in more abstract and applied areas like Engineering and Physical Sciences [5]. The technology field (engineering, computer sciences, and medical technology) tends to be dominated by Kolb's "Convergers" learning style. Another study found a significant difference in the patterns of preference for learning style type between Diesel Technology programs and Practical Nursing programs in postsecondary vocational technical education programs [3].

Some research suggests learners select occupations in which colleagues have a similar type of learning style while others may adopt the learning style characteristics of their colleagues [4]. This relates to Kolb's findings that professional orientation shapes learning style as a result of a variety of factors an individual is exposed to such as the specialized learning environment within one's professional career, the influence of colleagues, and the common set of values and beliefs shared within the profession [4].

\section{(3) Differences in Strength of Learning Style Type by Gender, Race, and Location}

Table 2 summarizes the results of our survey when comparing the strength of student preference for each learning style type by gender, race, and location. Variances were tested for equality using BrownForsythe and when different, the p-value and its test use the Welch Anova. Our analysis indicated a significant difference in the strength of learning style type for both visual and auditory learning styles based on gender. There was no difference for kinesthetic learners based on gender. Female students scored higher in the strength of both their visual and auditory learning styles over male students. Analysis of the data based on race (white vs. non-white) showed a significant difference in the strength of learning style for auditory learning. Non-white students scored higher in the strength of their auditory learning style over white students.

Table 2. Comparison of Strength of Learning Style Type by Gender and Race

\begin{tabular}{|l|c|c|c|c|c|c|c|c|}
\hline & \multicolumn{2}{|c|}{ GENDER } & \multicolumn{2}{c|}{ RACE } & \multicolumn{2}{c|}{ Mean } & \multicolumn{2}{c|}{ p-value } \\
\hline Learning Style & Female & Male & $\begin{array}{c}\text { Different/ } \\
\text { Equal }\end{array}$ & $\begin{array}{c}\text { Level of } \\
\text { sig.=0.05 }\end{array}$ & White & $\begin{array}{c}\text { Non- } \\
\text { white }\end{array}$ & $\begin{array}{c}\text { Different/ } \\
\text { Equal }\end{array}$ & $\begin{array}{c}\text { Level of } \\
\text { sig.=0.05 }\end{array}$ \\
\hline Visual & 6.02 & 5.15 & Different & $<.0001$ & 5.72 & 5.89 & Equal & .1512 \\
\hline Auditory & 7.33 & 6.58 & Different & $<.0001$ & 6.88 & 7.31 & Different & $<.0001$ \\
\hline Kinesthetic & 6.03 & 6.28 & Equal & $<.001$ & 6.30 & 6.32 & Equal & .9072 \\
\hline
\end{tabular}

Table 3 shows a significant difference in the strength of each of the learning style types based on the location (Georgia, Michigan, and South Dakota) of the schools that participated in the study. Our analysis showed a significant difference in the strength of learning style type with South Dakota students scoring higher for both visual and kinesthetic learning styles and Georgia students scoring higher for auditory learning style.

Table 3. Comparison of Strength of Learning Style Type by Location

\begin{tabular}{|l|c|c|c|c|c|}
\hline & \multicolumn{3}{|c|}{ MOCATION (by state) } \\
\hline & \multicolumn{3}{|c|}{ Mean } & \multicolumn{3}{c|}{ p-value } \\
\hline Learning Style & Georgia & Michigan & South Dakota & $\begin{array}{c}\text { Different/ } \\
\text { Equal }\end{array}$ & $\begin{array}{c}\text { Level of } \\
\text { Sig.=0.05 }\end{array}$ \\
\hline Visual & 5.91 & 5.39 & 6.56 & Different & $<.0001$ \\
\hline Auditory & 7.20 & 6.94 & 6.79 & Different & $<.0182$ \\
\hline Kinesthetic & 6.10 & 6.20 & 6.93 & Different & $<.0001$ \\
\hline
\end{tabular}




\section{(4) Change in Learning Style Types}

Our study showed a significant difference $(p=0.05)$ when comparing the learning style types by age of students using regression analysis. For this analysis, the learning style measure is specified by linear formula (Learning style $=\boldsymbol{\alpha}+\boldsymbol{\beta} *$ Age). As indicated by the $\boldsymbol{\beta}$-value (Table 4 ), there was a decrease in the learning style measure for both visual and kinesthetic learners as age increased. On the other hand, the learning style measure for auditory learners increased with age.
Figure 1 shows the percentage of each learning style type for each grade level. The results show a statistically significant difference in learning style type for each grade level. There was an increase in the percentage of students whose predominant learning style type is auditory as grade level increases, peaking at 63.79 percent in grade 9 from a starting point of 29.49 percent in grade 4 .

Figure 1. Percentage of Learning Style Type by Grade Level

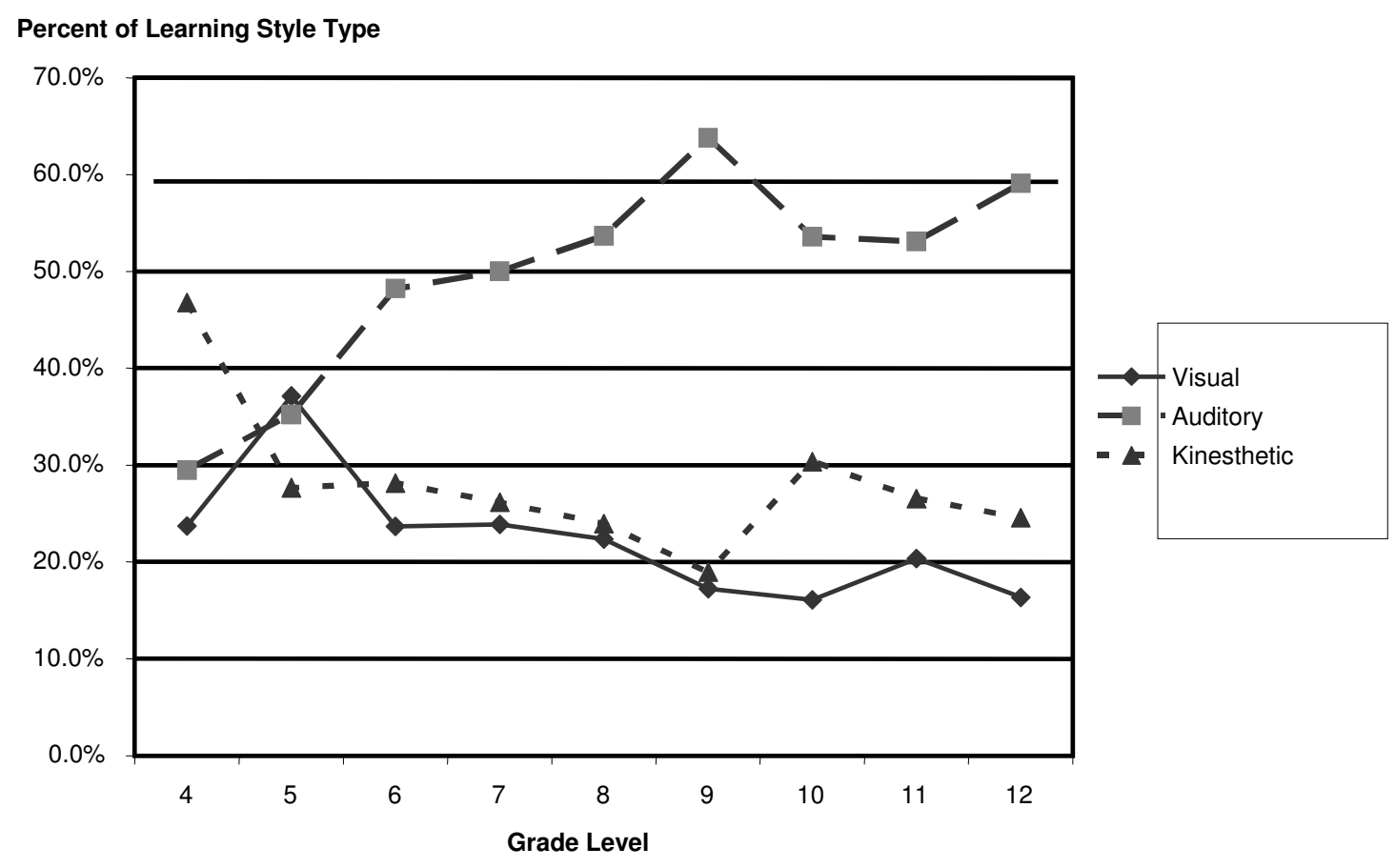

\section{CONCLUSIONS}

The review of the literature strongly indicates how important understanding learning styles and the role of learning styles in the teaching/learning process is for effective teaching. When teachers and students understand how they learn and their preferred ways to learn, the probability for learning increases. The literature also indicates a difference in the learning style types of students in different academic programs. Patterns in learning style type have been identified in select occupations and academic programs. In addition, research has shown that individuals have adopted the learning style characteristics of those they work closely with, also contributing to an occupational pattern of learning style types. A set of specific factors have been identified that shape and influence our learning styles throughout our lives. This is consistent with the findings of this study related to the change in students' learning style type as they progress through their education.

Findings from the data gathered for this study show differences in learning style type based on gender, race, and geographic location. The data also suggests a change in students' learning style type as they progress through their education. This pattern could be interpreted as an adjustment students make in order to accommodate how teachers are teaching. As 
students move to higher grade levels, one could assume lecture becomes a bigger part of what takes place in the typical classroom. Students may be forced to learn in more auditory ways as a result of the one-way teaching style of teachers (which may not necessarily better prepare them for their occupational area).

\section{RECOMMENDATIONS}

Based on our findings, we would recommend against extensive use of the lecture method by faculty at the postsecondary level, as it would continue to focus on only auditory learners and auditory skills. The lecture format allows students to continue to develop their auditory skills at the risk of minimizing or stunting the development of other modes of learning. In addition, students need to develop workplace skills more closely related to visual and kinesthetic learning style characteristics, particularly in occupational areas such as IT. Professional orientation appears to be an important factor in shaping the learning style of individuals. The specialized learning environment of the IT field could easily provide this influence. IT faculty could provide a great benefit to students by simulating or modeling this learning environment in their classrooms as much as possible and to be aware of the learning style characteristics of this environment. Therefore, IT courses should specifically utilize kinesthetic learning to build students capabilities with this learning style.

\section{REFERENCES}

1. Cross, P. K. (2001). Leading-edge efforts to improve teaching and learning, the Hesburgh awards. Change, 33(4) July/August, 30-37.

2. Dunn, R., S. A. Griggs, J. Olson, B. Gorman, M. Beasley (1995). A meta-analytic validation of the Dunn and Dunn learning styles model. Journal of Educational Research, 88(6), 353-361.

3. Gray, R. L. (2003). Identifying predominant learning styles of students in diesel technology and practical nursing programs. Unpublished doctoral dissertation, Montana State University, Bozeman.

4. Kolb, D. (1984). Experiential learning experience as the source of learning and development. New Jersey: Prentice-Hall, Inc.

5. Kolb, D., Boyatzis, R., \& Mainemelis, C. (2000). Experiential learning theory: Previous research and new directions. Retrieved July 24, 2005, from http://www.learningfromexperience.com/ research-library/.

6. Sarasin, L. C. (1999). Learning style perspectives: Impact in the classroom. Madison, WI: Atwood Publishing.

7. Shaughnessy, M. F. (1998, January). An interview with Rita Dunn about learning styles. Clearing House, (71)3, (OCLC FirstSearch: Full Text).

8. Sims, R. R. \& Sims, S. J. (Eds.) (1995). The importance of learning styles: Understanding the implications for learning, course design, and education. Westport, CT: Greenwood Press. 